\title{
THE SCOTTISH TEN PROJECT: COLLABORATIVE HERITAGE DOCUMENTATION
}

\author{
L. Wilson ${ }^{\text {a, } * \text {, A. Rawlinson }}{ }^{\text {b D.S. Mitchell }}{ }^{\text {a }}$, H.C. McGregor ${ }^{\text {a }}$, R Parsons ${ }^{\text {c }}$ \\ ${ }^{a}$ Historic Scotland, Longmore House, Salisbury Place, Edinburgh, EH9 1SH, Scotland \\ (lyn.wilson, david.mitchell, chris.mcgregor)@ scotland.gsi.gov.uk \\ ${ }^{\mathrm{b}}$ Digital Design Studio, Glasgow School of Art, The Hub, Pacific Quay, Glasgow, G51 1EA, Scotland - \\ a.rawlinson@gsa.ac.uk \\ ${ }^{c}$ CyArk Europe, 152 Morrison Street Edinburgh, EH3 8EB \\ ruth.parsons@cyark.org
}

KEY WORDS: Laser scanning, 3D visualisation, heritage, digital preservation, UNESCO World Heritage Sites.

\begin{abstract}
:
The Scottish Ten project is a five-year initiative of the Scottish Government to digitally document significant heritage sites around the world for future generations both in Scotland and overseas. The project is fundamentally grounded in collaboration and is delivered by Historic Scotland and the Digital Design Studio at Glasgow School of Art, in partnership with CyArk. In addition, the Scottish Ten team collaborate with local partners at each site to deliver products which will be of use to site managers in the ongoing conservation, management and interpretation of their sites. The project utilises diverse 3D data capture methods, as appropriate for each site, but the foundation of the documentation lies in terrestrial laser scanning. This paper explores the collaborations, methodologies and gives brief case studies from one Scottish and one international site.
\end{abstract}

\section{INTRODUCTION}

\subsection{The Scottish Ten Project}

The Scottish Ten is an ambitious five-year project using cutting edge technology to create accurate digital models of Scotland's five UNESCO designated World Heritage Sites (WHS) and five international heritage sites in order to better conserve and manage them.

The primary aims of the Scottish Ten project are to:

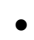

Digitally document and preserve important historical sites for the benefit of future generations in Scotland and overseas.

- $\quad$ Share and promote Scottish technical expertise in conservation and digital visualisation.

- Foster international collaboration and build lasting partnerships that capitalise on cultural connections with Scotland.

- $\quad$ Provide 3D digital models and data to site staff to better care for the heritage asset.

Create digital documentation and accurate 3D
surveys of the sites for future development of world class and innovative research, education and management.

In 2009 Ben Kacyra spoke at the Digital Documentation Conference in Glasgow, Scotland about CyArk, the non-profit foundation he had founded to create a database of digital information on globally significant heritage sites. CyArk's aim would be to encourage the use of this data for conservation and maintenance and to ensure that should any of these sites become damaged there would be a lasting record of them and what they meant to the cultures that created them: in effect, creating a digital preservation record or a CYber ARKive.

At this time, Ben Kacyra met with the Scottish Government's then Minister for Culture Michael Russell and representatives from Historic Scotland and the Digital Design Studio at Glasgow School of Art. Mr. Russell committed the Scottish Government to digitally preserving Scotland's five UNESCO recognised World Heritage Sites plus five international heritage sites to contribute to the CyArk vision - the Scottish Ten Project.

\subsection{Project Scope}

The scope of the Scottish Ten project is wide-ranging. It seeks to digitally document Scotland's five World Heritage Sites, which represent very different aspects and achievements in Scotlands' history. The sites are: The Heart of Neolithic Orkney, the Antonine Wall (part of the Frontiers of the Roman Empire World Heritage Site), The Old and New Towns of Edinburgh and New Lanark cotton mill complex. All of these are recognised for their global cultural significance. The fifth Scottish site are the remote islands of St Kilda which is the UK's only World Heritage Site designated for both its cultural and natural significance.

The international sites are selected to fulfil Scottish Government international objectives and to date have involved projects in North America, India, China and Australia. The team has completed work on the Mount Rushmore National Memorial, in South Dakota, USA, Rani ki Vav stepwell in Gujarat, India, the Eastern Qing Tombs in Zunhua, China and the Sydney Opera House in Australia. The fifth site will be selected and announced in due course.

\footnotetext{
* Corresponding author.
} 
Each site poses its own particular challenges and we work closely with partners to get the best possible local knowledge and expertise in conservation and access. Sharing the information we collect with these collaborators allows us to look at what the most appropriate way to process it is.

\section{COLLABORATIVE PARTNERS}

\subsection{Historic Scotland}

Historic Scotland is the national heritage agency of the Scottish Government and is directly responsible to Scottish Ministers for safeguarding the nation's historic environment, and promoting its understanding and enjoyment. Its role is to advise on all aspects of the historic environment and carry out statutory functions concerning planning consents. Historic Scotland (HS) staff are experts in a range of disciplines and skills from archaeologists to conservators and scientists, custodians and award-winning visitor services. In recent years it has developed professionally recognised qualifications in traditional skills training, unveiled world-class improvements to the attractions in its care and invested millions of pounds in conservation projects across Scotland to safeguard the nation's heritage for present and future generations.

\subsection{Digital Design Studio, Glasgow School of Art}

The Glasgow School of Art is internationally recognised as one of Europe's foremost university-level institutions for creative education and research in fine art, design and architecture. The Digital Design Studio (DDS) is a state of the art research centre of Glasgow School of Art focusing on developing cutting edge real-time 3D visualization and interaction technologies. The DDS is a proactive leader in the development of new technologies, tools, techniques and methodologies that support new media and digital content creation. In particular, core research focuses on developing new techniques for interaction, user oriented interfaces, haptics, gesture, 3D sound and realtime photorealistic $3 \mathrm{D}$ visualization.

\subsection{CyArk}

CyArk's origin is traced back to the founding of Cyra Technologies in 1993 by Ben and Barbara Kacyra. Cyra was the first to develop and bring to market the first commercially available integrated system of high-resolution 3D laser scanning and cloud of point software for the architecture/engineering/construction, plant management, and media/entertainment industries. In 2001 Cyra Technologies was acquired by Leica Geosystems. The Kacyra Family Foundation was founded in 2000 by Ben and Barbara Kacyra as a 501(c) 3 charitable trust with part of its mission being the preservation of cultural heritage sites. CyArk was created in 2003 as a nonprofit project of KFF and became an independent organisation in 2008.

Today, CyArk and its recently established sister organization CyArk Europe, are non profit organisations with the mission of digitally preserving cultural heritage sites through collecting, archiving and providing open access to data created by laser scanning, digital modeling, and other state-of-the-art technologies. A key part of CyArk's mission is to utilize technology to tell cultural stories in a way that was never before possible.
CyArk is a leader in digital preservation of cultural heritage sites. It has provided a facility to accept digital preservation data from partners from over one hundred heritage sites around the world including Pompeii, Italy, Chichen Itza, Mexico, Angkor Wat, Cambodia and Ancient Thebes, Egypt.

\subsection{Site Specific Partners}

On each of the Scottish Ten sites, engagement is made at the outset with the site managers and other groups interested in the protection, preservation and access to the monuments. They are involved throughout the project and help the Scottish Ten team to prepare for the fieldwork and overcome potential obstacles and providing invaluable local knowledge. This expertise and the management needs of the people who look after these incredible sites also helps to identify what type of data development will have the greatest benefit in its long term preservation and presentation.

With the international sites, Historic Scotland leads on the development of a government-government Memorandum of Understanding to facilitate each stage of the project. For Mount Rushmore, this involved an agreement with the US National Park Service, for Rani ki Vav the relationship was with the Archaeological Survey of India, the government heritage body. In China, the State Administration of Cultural Heritage were the principal government partner and in Sydney, the Sydney Opera House Trust and New South Wales Government participated in the agreements.

\subsection{Roles and Practicalities of Partnerships}

Historic Scotland and Glasgow School of Art established a limited liability partnership, the Centre for Digital Documentation and Visualisation (CDDV) in 2010, on behalf of the Scottish Government to deliver the Scottish Ten and other select projects using cutting edge technology together with renowned expertise from both HS and DDS. The CDDV partnership promotes and celebrates Scotland's cultural heritage at home and abroad and enhances Scotland's reputation for developing world class and innovative research and development.

Historic Scotland leads on selection of the international sites in association with Scottish Ministers. HS then works to facilitate the agreements to allow the projects to take place. The Scottish Ten project contributed to positive international engagement between governments, referred to as "cultural diplomacy".

A diverse team of specialists including archaeologists, scientists, surveyors, architects, visualization specialists and designers from both DDS, HS and CyArk take part in the data acquisition at each site before the data is processed and developed into heritage visualisation tools at the Digital Design Studio. The Historic Scotland team is responsible for production of any conservation applications derived from the data, such as CAD drawings or condition monitoring tools.

CyArk functions in an advisory role for the Scottish Ten, and a member of the CyArk team provides on-site project support for the international sites. On large-scale complex projects this is a critical data management role. In addition, CyArk will play a key role in the archiving and dissemination of the Scottish Ten data. 


\section{METHODOLOGY}

\subsection{Data Acquisition}

A variety of data acquisition methodologies are employed on Scottish Ten projects, however terrestrial laser scanning underpins the overarching strategy. These ground-based laser scans are acquired through traverses and resections, with supplementary free scans, following English Heritage's metric survey guidelines (Andrews et al., 2010, Barber, 2011) and CyArk's Digital Preservation Standards (CyArk, 2009). GNSS georeferencing of each site positions the laser scan survey into real-world coordinate systems. The average acquired point to point spacing on Scottish Ten projects is $5 \mathrm{~mm}$ for the heritage site and $50 \mathrm{~mm}$ for its contextual setting. Another fundamental of the Scottish Ten methodology is that high-dynamic-range 360 degree panoramic photographs are acquired from the same nodal point as each scan position to allow full high definition photo-texturing of the model derived from the point cloud data. Metadata is recorded for each data capture set-up.

In addition, for the Scottish World Heritage Sites, $0.5 \mathrm{~m}$ airborne LiDAR data and orthophotos have been acquired to provide extensive coverage of the entire world heritage zone. On particular sites, mobile laser mapping, long-range laser scanning and close-range structured light scanning have been utilised where appropriate to accurately and completely document the site.

Several of the Scottish Ten sites have posed logistical and technical challenges for digital documentation. At Mount Rushmore, Rani ki Vav and Sydney Opera House, there were areas of the site that were invisible from any accessible scan locations. To circumvent this issue, custom designed mounts and rigs were fabricated to permit $100 \%$ data acquisition. In each case, the Scottish Ten team has collaborated with rope access specialists to facilitate the safe execution of these scans.

\subsection{Data Processing}

The raw data from the multiple laser scans and structured light scans are firstly registered and georeferenced. The full point cloud is then meshed to create a 3D model. For most of the Scottish Ten sites, a high-resolution model derived from the mesh is photo-textured using the HDR imagery collected on site to generate a fully photo-realistic 3D model.

From this, orthorectified scalable images are produced, often 2D CAD drawings and high definition imagery. Virtual tours of the sites are created via animated site fly-throughs of the point cloud or 3D model.

\subsection{Archiving}

All 3D data collected is archived in non-proprietary ASCII format with metadata on secure servers at Historic Scotland, the Digital Design Studio and with CyArk. In addition, a digital preservation report is written to complement the $3 \mathrm{D}$ record. For the international Scottish Ten sites, the full 3D dataset and intellectual property is gifted from the Scottish Government to the national heritage body managing that site in the spirit of partnership and further collaborative working.

\subsection{Dissemination}

Sharing and dissemination of the Scottish Ten data is one of the project's main aims. This is facilitated in several ways. Initially, information on the projects is posted on the Scottish Ten website (www.scottishten.org) and on the CyArk website (http://archive.cyark.org) and using social media (www.twitter.com/scottishten). Via the CyArk portal, a Scottish Ten Gallery of 3D data will be made available to site managers and the public.

To ensure dissemination of the Scottish Ten data is most effective, the team works with site managers to assess how best the 3D data can be presented. In the case of the Mount Rushmore project, CyArk worked with the National Park Service to develop a series of new-media applications for education and interpretive purposes derived from the terrestrial scan data and 3D models.

\section{CASE STUDY: NEW LANARK, SCOTLAND}

\subsection{New Lanark Site Background}

The village of New Lanark is located in a stunning valley setting close to the famous Falls of Clyde and surrounded by native woodlands (Figure 1). It was founded in 1785 by David Dale as a completely new type of industrial settlement. Cottonspinning mills, powered by water from the River Clyde, and tenement style housing for the workforce were built from local sandstone. Under the management of Dale's son-in-law, Robert Owen, the village became a model industrial community, with no child labour or corporal punishment and with provision of good housing, schools, free health care and affordable food for the villagers. By 1820, the population of the village was around 2,500 , and it was the largest cotton-manufacturing centre in the country (Donnachie and Hewitt 1993). It is now a popular tourist attraction managed by New Lanark Trust and is home to the New Lanark Visitor Centre and New Lanark Mill Hotel. It became a UNESCO World Heritage Site in 2001.

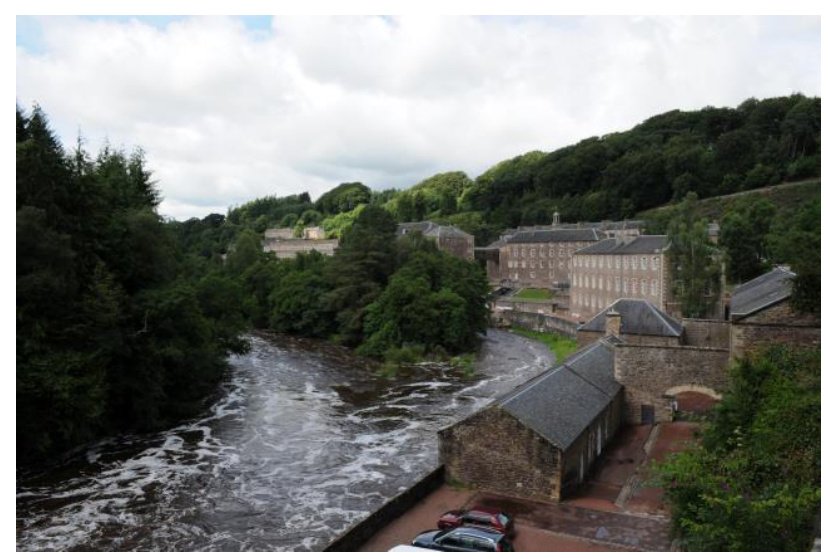

Figure 1. New Lanark village ${ }^{\circledR}$ CDDV 2009.

\subsection{Project Methodology at New Lanark}

Through engagement with New Lanark Trust, Historic Scotland and the Digital Design Studio undertook a programme of 3D survey to encompass the entire site at New Lanark during 2009. The ground-based work included terrestrial laser scanning using both time-of-flight (Leica ScanStation 2) and phase-shift (Leica 
HDS 6100) scanners (Figure 2), and HDR 360 degree photography, using a Nikon D3X camera and Nodal Ninja ${ }^{\circledR} 5$ camera mount to position the nodal point of the camera lens at the same height as the laser sensor within the scanner. In total, over 100 scans were made. Accurate positioning was enabled by use of Leica 1200+ GNSS system. In addition, airborne LiDAR and orthophotos were collected for the entire site at $0.5 \mathrm{~m}$ point spacing.

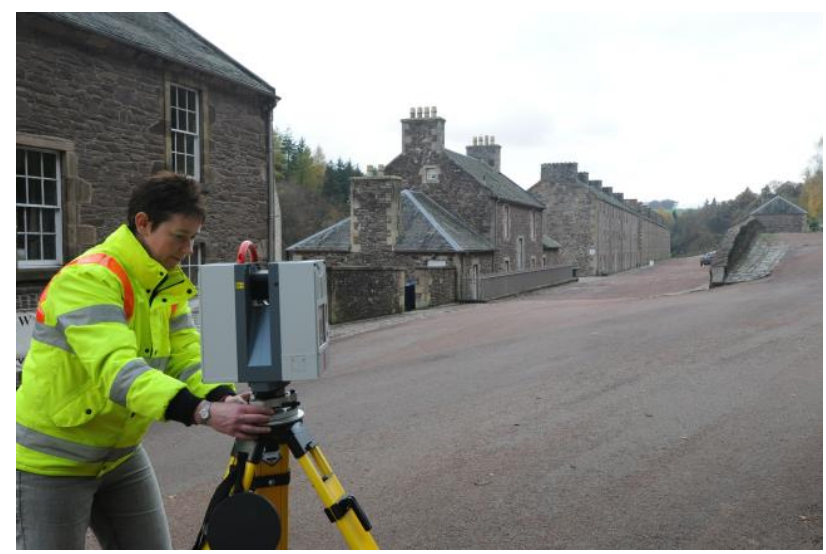

Figure 2. Terrestrial laser scanning with a phase-shift scanner at New Lanark ${ }^{\circledR}$ CDDV 2009.

\subsection{Deliverables}

A precise 3D survey of New Lanark for digital archive purposes was the first main deliverable from the Scottish Ten project. In addition, detailed 2D CAD drawings of all main buildings within the village were prepared directly from the $3 \mathrm{D}$ point cloud. These will be used by New Lanark Trust in the ongoing conservation and maintenance of the village.

A fully photo-realistic model (Figure 3) was generated for the entire village and working closely with New Lanark Trust, this was developed into a virtual tour, interlaced with archival imagery and oral histories. New Lanark Trust now use this tour as an educational resource within their visitor centre and it will soon be available to view on their website.

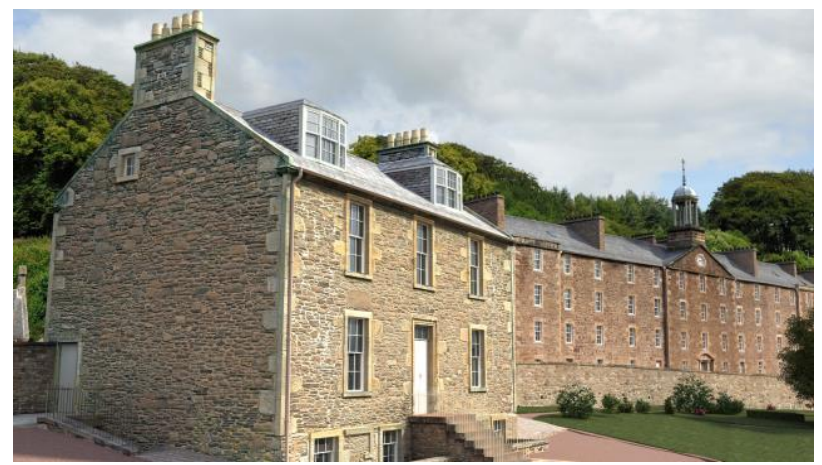

Figure 3. Photo-realistic model of Robert Owen's House at New Lanark ${ }^{\circledR}$ CDDV 2010.

The Scottish Ten are seeking further collaborative funding with New Lanark Trust to use the 3D dataset for re-interpretation of houses within the village (Figure 4) and to explore how 3D imagery can facilitate learning and understanding.

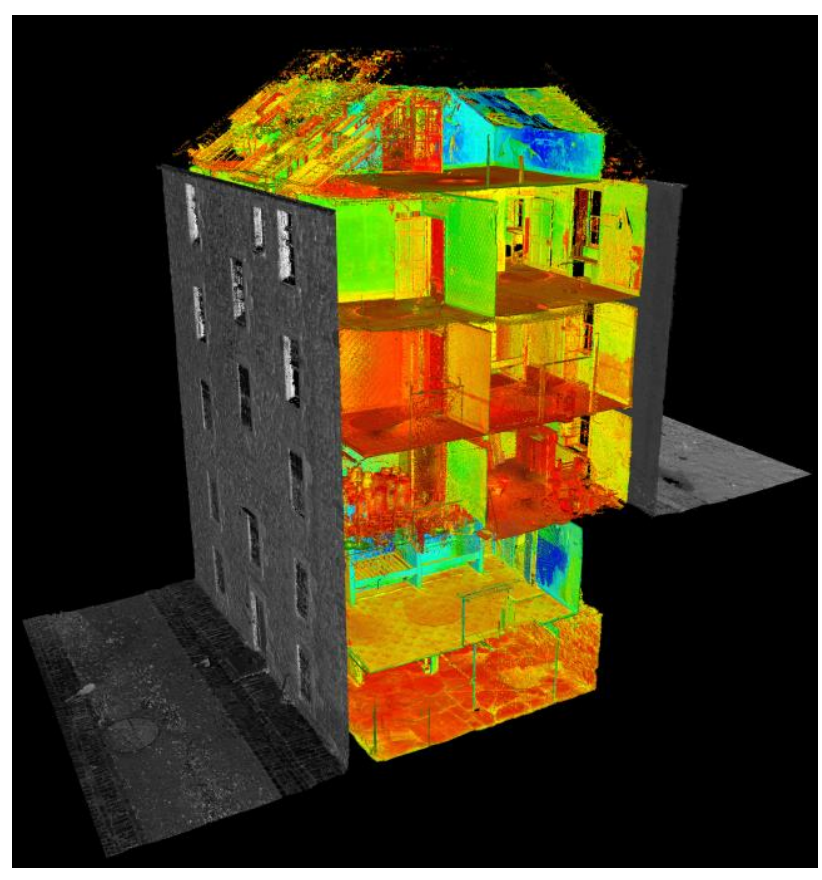

Figure 4. Point cloud image of the 'Museum Stair' building within New Lanark village ${ }^{\circledR}$ CDDV 2013.

Community engagement was an important part of the project at New Lanark and in 2012 the Scottish Ten ran a schools workshop in partnership with New Lanark Trust. This focused on the principles of 3D survey and 3D design with the students gaining hands-on experience in survey measurements, photography, laser scanning and 3D modelling using Google Sketchup ${ }^{\circledR}$ to produce their own 3D model of a building at New Lanark (Figure 5).

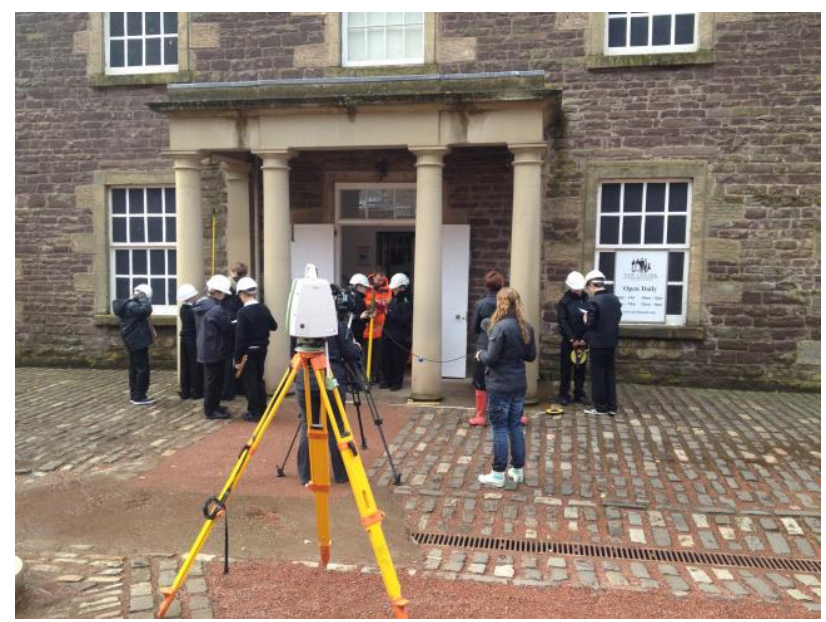

Figure 5. Schools workshop on 3D survey and design at New Lanark ${ }^{\circledR}$ CDDV 2012.

The Scottish Ten partners will continue to work with New Lanark Trust to maximise the benefits of the versatile 3D dataset. 


\section{CASE STUDY: RANI KI VAV, INDIA}

\subsection{Rani ki Vav Site Background}

The Rani-ki-Vav (Queen's stepwell) located at Patan, the mediaeval capital of Gujarat from about $10^{\text {th }}$ to $13^{\text {th }}$ century A.D., was built by Queen Udayamati, consort of Solanki king Bhimdev in 1050 A.D. The Queen commissioned construction of this Vav (well) in honour of her deceased husband as per the practice sanctioned by tradition and Indian religious texts (Mankodi, 1991). Amongst thousands of stepwells, this is the largest stepwell of its kind in India. The Vav measures $65 \mathrm{~m}$ in length, $20 \mathrm{~m}$ in width, and $25 \mathrm{~m}$ in depth, with a well-shaft, 10 $\mathrm{m}$ in diameter (Archaeological Survey of India, 2012). The Vav is seven storeys deep and is interposed with 4 tower pavilions raised across at regular intervals (Figure 6). The outstanding value of the Vav lies in its architectural form and exceptionally rich sculptural imagery manifesting on the North and South walls of the stepped corridor and inside the well shaft (Figure 7).

The site was only re-discovered in the 1950s as it's many levels had been backfilled with silt over the centuries. As a result the ornate carvings are excellently preserved.

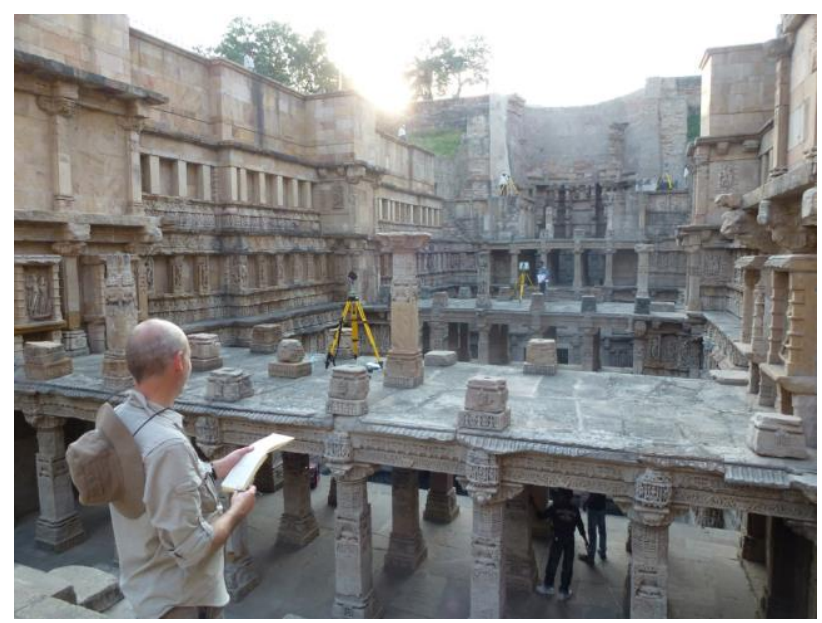

Figure 6. Rani ki Vav stepwell, Gujarat, India ${ }^{\circledR}$ CDDV 2011.

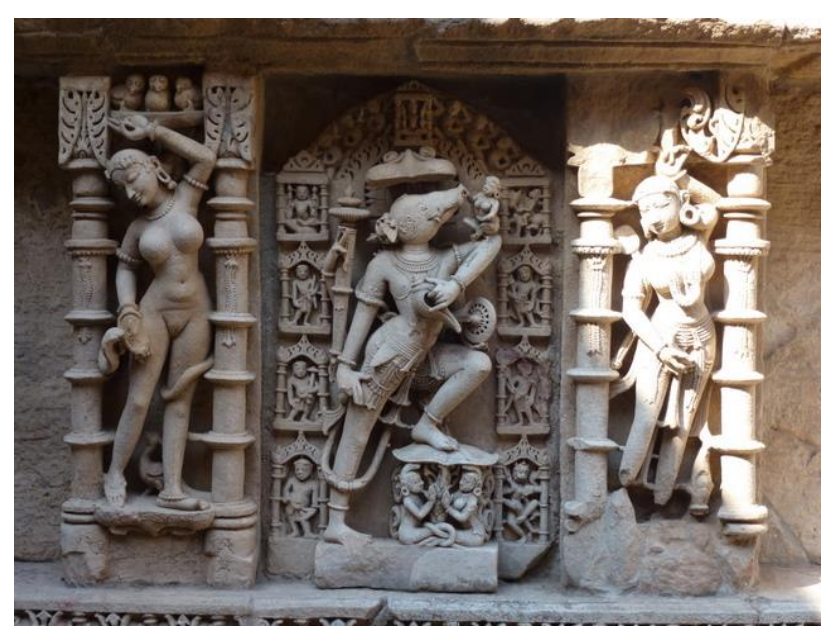

Figure 7. Sculptural detail at Rani ki Vav stepwell, Gujarat, India ${ }^{\odot}$ CDDV 2011.

\subsection{Project Methodology at Rani ki Vav}

In October 2011, the Scottish Ten team undertook a programme of work over two weeks to complete a comprehensive and accurate 3D digital survey of Rani ki Vav. The team comprised members of staff from Historic Scotland, Glasgow School of Art's Digital Design Studio and CyArk and worked closely with colleagues from the Archaeological Survey of India (ASI) throughout the duration of the project, tutoring them in the use of 3D scan systems.

The approach involved a number of 3D survey technologies including terrestrial laser scanning (using both time-of-flight and phase-shift scanners) (Figure 6), 360 degree HDR photography and close-range sub-millimetre structured light scanning of sculptures. In total, the team completed 176 scans, working to an accuracy of $5 \mathrm{~mm}$, plus multiple close-range scans using an Artec MHT. As the project was a collaborative venture, the ASI team undertook a total station survey, which tied into our laser scan traverses, thus enabling the 3D scanning to be aligned on the Indian National Grid.

To allow complete data coverage of the stepwell, the Scottish Ten team designed and built an adaptable rig onto which the Leica 6100 scanner was attached and in collaboration with Global Remote, a specialist rope access team, the scanner was positioned over the centre of the well and operated remotely via Wi-Fi (Figure 8).

CyArk's role at Rani ki Vav was in on-site data management. As scans were completed, they were passed to the CyArk team for download, backup, import and database compilation. Having a dedicated data manager was critical to ensure there were no voids in the data.

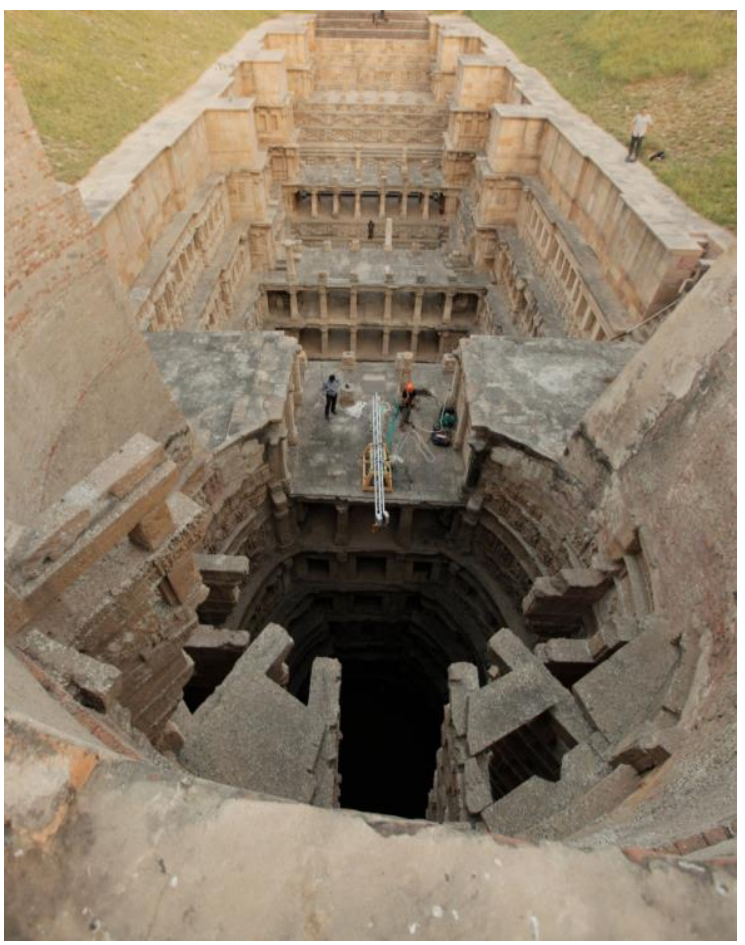

Figure 8 . Specially designed rig with laser scanner attached and suspended over centre of well to capture areas not visible from other vantage points ${ }^{\circledR}$ CDDV 2011. 


\subsection{Deliverables}

The project generated a very accurate, high-resolution 3D survey, which the ASI are using for conservation and heritage management strategies. All survey data and multimedia derivatives have been supplied to the ASI in digital format, as per the mission of the Scottish Ten collaboration. At the request of the ASI, ortho-rectified scalable 2D plans and sections were generated from the point cloud data (Figure 9). A full 3D model was delivered, which can be used as an interpretation and education tool and as a visual aid to understanding the construction and iconography (Figure 10). Furthermore, an animation of the 3D model, including gigapixel photography, was produced with a descriptive narrative in Hindi, Gujarati and English. This, along with interactive QuickTime Virtual Reality panoramas produced, will help deliver remote access and virtual tours.

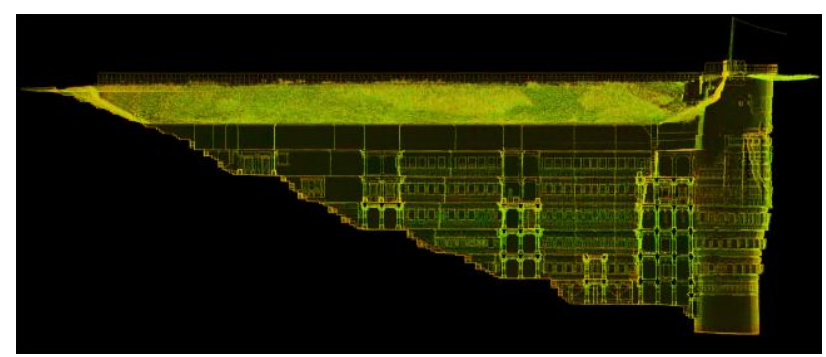

Figure 9. Point cloud cross section through the Rani ki Vav stepwell ${ }^{\circledR}$ CDDV 2012.

Despite its architectural significance, Rani ki Vav is not widely known outside India and currently sits on UNESCO's Tentative List for World Heritage Status. By digitally documenting Rani ki Vav for the Scottish Ten project, the Scottish Ten team aimed to bring the site to a much wider audience and raise both its national and international profile. The ASI has submitted a bid to UNESCO for full inclusion on the WHS list, and Scottish Ten project data and derivatives have formed part of this proposal.

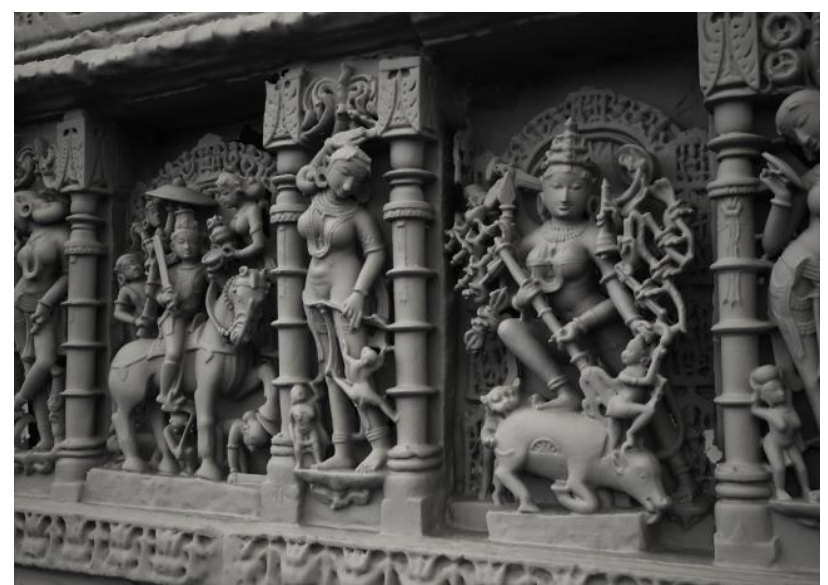

Figure 10. Mesh of sculpture obtained from close-range structured light scanning at Rani ki Vav ${ }^{\odot}$ CDDV 2012.

Historic Scotland is currently in discussion with the ASI to bring their surveyors to Scotland to continue the knowledge sharing and partnership working established on site in India. The vision is that the Scottish Ten project will form the basis of a long-term relationship with the ASI and serve to build capacity in the field of digital heritage documentation.

\section{CONCLUSIONS}

The Scottish Ten project relies fundamentally on a collaborative approach to digital documentation. Drawing strengths from all partners allows for the comprehensive recording of each site in the project's portfolio to digitally safeguard it and to provide accurate and practical digital tools for their continuing conservation, management and enjoyment.

The challenges faced by working with a broad range of partners at international and local level added to the interest and complexity of each project and demanded the greatest respect for all cultures working together for the benefit of the heritage site and local area. It also demanded great attention to detail in managing the logistics of bringing teams and equipment together at international sites, at the right time to ensure the smooth running of the project.

However, the challenges were significantly outweighed by the success of the project aims to date where hugely culturally significant sites have been digitally preserved with information used to enhance their conservation and dissemination.

In addition, the experience gained by working together on site and the transfer of skills between the organisations has increased the capability of all of the partners involved.

It is hoped that the success of the Scottish Ten Project will generate global interest and lead to further projects to digitally preserve the world's cultural heritage.

\section{REFERENCES}

Andrews, D., Bedford, J., Blake, B, Bryan, P., Cromwell, T. and Lea, R. 2010. Measured and Drawn: Techniques and Practice for the Metric Survey of Historic Buildings ( $2^{\text {nd }}$ edition, edited by J. Bedford and H. Papworth). English Heritage, Swindon.

Archaeological Survey of India, 2012. Rani ki Vav. Justification for Inscription in UNESCO World Heritage List, Unpublished.

Barber, D. 2011. 3D Laser Scanning for Heritage: Advice and Guidance to Users on Laser Scanning in Archaeology and Architecture ( $2^{\text {nd }}$ edition). English Heritage, Swindon.

CyArk. 2009. The CyArk 500 Project Standards and Procedures. Unpublished report.

Donnachie, I. and Hewitt, G. 1993. Historic New Lanark. Edinburgh University Press, Edinburgh.

Mankodi, K. 1991. The Queen's Stepwell at Patan. Project for Indian Cultural Studies, Publication III. Franco-Indian Research Pvt. Ltd., Bombay. 